EESTI NSV TEADUSTE AKADEEMIA TOIMETISED. XVII KOIDE

KEEMIA * GEOLOOGIA. 1968, Nr. I

ИЗВЕСТИЯ АКАДЕМИИ НАУК ЭСТОНСКОИ ССР ТОМ ХVII

ХИМня * ГЕОЛОГия. 1968, 추 1

Р. ПРИИМАН, Л. ПААЛЬМЕ

\title{
МЕТОД ОПРЕДЕЛЕНИЯ КОНЦЕНТРАЦИИ НАТРИЕВОИ СОЛИ СУЛЬФОКИСЛОТЫ ИЗОПРОПИЛБЕНЗЕНА ПО ХИМИЧЕСКОМУ ПОТРЕБЛЕНИЮ КИСЛОРОДА В ПРОЦЕССЕ ЕГО ОКИСЛЕНИЯ
}

Изучение кинетики мягкого окисления сульфопроизводных изопропилбензена в составе сложных смесей молекулярным кислородом требует применения точных методов определения химического потребления кислорода в процессе окисления и концентрации реагирующего (или окисленного) вещества в смеси. Это особенно важно при использовании методики кинетического исследования, описанной в сообщении [1], ибо изменение концентрации солей сульфокислот алкилбензенов с короткой и разветвленной цепью, вследствие их низкой реакционной способности, связано иногда с весьма незначительными изменениями концентрации реагента во времени. При этом даже небольшие погрешности аналитического определения вносят существенную неточность в результаты кинетического исследования.

Методы определения концентрации солей сульфокислот алкилбензенов, обладающих, как правило, поверхностно-активными свойствами (ПАВ), в технических смесях и растворах немногочисленны и не отличаются высокой точностью [3-5]. Наиболее распространен колориметрихеский способ определения ПАВ в виде комплекса с метиленовым голубым в хлороформе $[2,3]$. Он страдает рядом существенных недостатков - сложностью, длительностью операций и недостаточной точностью, которая выражается в значительном расхождении результатов параллельных определений.

Значительно большей точностью и относительной простотой облацает разработанный нами метод количественного определения содержания натриевой соли сульфокислоты изопропилбензена в реагирующей смеси по химическому потреблению кислорода (ХПК) при жестком окислении ее бихроматом калия в концентрированной серной кислоте. Экспериментальная разработка его произведена на смеси (порошке), в состав которой входит $35,0 \%$ указанного соединения (сннтезированного на основе многократно очищенного кумола с проверкой по физико-химическим показателям) и неокисляемые неорганические соединения - гидроокись, сульфат и карбонат натрия.

Химическое потребление кислорода определено для шроб водного раствора такой смеси как без обработки (эталонной), так и подвергнутой предварительно частичному окислению в ходе кинетического эксперимента молекулярным кислородом при различных температурных уровнях и длительности в присутствии катализаторов и без них. Методика аналитического эксперимента сводится к следующему. 
В две колбы Эрленмейера емкостью по 100 мл помещаетсл по 2 мл водного раствора испытуемой пробы, подвергнутой гастичному окислению, и так называемого стандартного раствора (исходного необработанного порошка в концентрации, соответствующей начальному уровню в кинетическом опыте). В зависимости от условий ведения кинетического эксперимента абсолютное количество сульфосоли кумола в указанной эталонной пробе составляет от 5 до 35 ме.

После полного удаления нз проб воды в термостате при $80^{\circ} \mathrm{C}$ в колбы вносится от 10 до 25 мл 0,4 н. раствора бихромата калия в концентрированной серной кислоте (реактив приготовлен на основе фиксаналов). Параллельно в третьей колсе ставится «холостой» эксперимент с одним лишь окислителем в той же дознровке.

Колбы, снабженные воздушными холодильниками, помещаются в металлическую ванну с терморегулятором и выдерживаются в течение 1 ч при температуре $150^{\circ}$ (точность $\left.\pm 0,1^{\circ}\right)$. После 15 -минутного охлаждения подвергнутые обработке растворы, трехкратно промытые 25 мл дистиллированной воды, переводятся в сосуды для титрования. Последнее производится 0,4 н. раствором соли Мора (приготовлеи с установлением точного титра по перманганату калия) при добавке двух капель нндикатора, 1\%-ного раствора дифениламина в $98 \%$-ной серной кислоте. Опыты дублируются.

Полученные данные по расходу соли Мора дают возможность определить количество кислорода, израсходованного на окисление стандартного раствора и испытуемой пробы. Величина ХПК, обычно выражаемая в граммах и на литр раствора испытуемого вещества заданной концентрации, определяется по формуле:

$$
\mathrm{X \Pi K}=\frac{8(a-b) N}{v},
$$

где $a$ и $b-$ расход соли Мора соответственно в холостой и стандартной (или испытуемой) пробах, $N$ - нормальность раствора соли Мора, v -- объем исследуемой исходной пробы.

\section{Полное окисление исходного продукта происходит по уравнению}

$$
2 \mathrm{C}_{9} \mathrm{H}_{11} \mathrm{SO}_{3} \mathrm{Na}+480 \rightarrow 18 \mathrm{CO}_{2}+10 \mathrm{H}_{2} \mathrm{O}+\mathrm{Na}_{2} \mathrm{SO}_{4}+\mathrm{H}_{2} \mathrm{SO}_{4} \text {. }
$$

Таким образом, на окисление моля активного вещества теоретически должно расходоваться 12 молей кислорода. По уравнению (1) определяется ХПК стандартного раствора и испытуемой пробы. Зная содержание активного вещества в стандартном растворе и соответствующее значение ХПК, можно вычислить содержание непрореагировавшего вещества (или степень окисления последнего) в пробе из кинетического опыта.

При этом нами экспериментально установлена линейная зависимость между концентрацией активного вещества (если количество его не составляет менее 1 мг) в растворе испытуемого порошка и величиной ХПК.

Параллельно с описанными экспериментами произведено фотоколориметрическое определение концентрации натриевой соли сульфокумола из тех же опытов с помощью метиленового голубого. Сопоставление полученных результатов приведено в таблице. Оно указывает на хорошее совпадение результатов определения по предлагаемой методике и подтверждает изложенные выше соображения о значительной неточности применяемого до настоящего времени способа аналитического определения ПАВ и степени их окисленности. 
Результаты параллельных определений степени окисленности натриевой соли сульфокислоты изопропилбензена в кинетических опытах по двум методам

\begin{tabular}{|c|c|c|c|c|c|c|c|c|}
\hline \multirow{2}{*}{\multicolumn{3}{|c|}{$\begin{array}{l}\text { Условия обработки в кинетическом } \\
\text { эксперименте }\end{array}$}} & \multicolumn{6}{|c|}{ Результаты өпределений по способам } \\
\hline & & & \multirow{2}{*}{\multicolumn{3}{|c|}{$\begin{array}{c}\text { колориметрическому } \\
\text { с метиленовым } \\
\text { голубым, \% }\end{array}$}} & \multirow{2}{*}{\multicolumn{3}{|c|}{$\begin{array}{c}\text { бихроматному по } \\
\text { ХПК, \% }\end{array}$}} \\
\hline \multirow{2}{*}{$\begin{array}{l}\text { темпера- } \\
\text { тура, }{ }^{\circ} \mathrm{C}\end{array}$} & \multirow{2}{*}{$\begin{array}{l}\text { длитель- } \\
\text { ность, ч }\end{array}$} & \multirow[b]{2}{*}{ иннциатор } & & & & & & \\
\hline & & & 1 & 2 & $\left|\begin{array}{l}\text { расхож- } \\
\text { дение, \% }\end{array}\right|$ & 1 & 2 & $\begin{array}{l}\text { расхож- } \\
\text { дение, \% }\end{array}$ \\
\hline 20 & 12 & & 2,0 & 3,1 & 35,5 & 1,9 & 2,0 & 5,0 \\
\hline 40 & 12 & & 4,0 & 3,1 & 22,5 & 2,8 & 3,0 & 6,5 \\
\hline 40 & 24 & & 16,3 & 12,8 & 21,4 & 16,1 & 15,7 & 2,4 \\
\hline 50 & 12 & & 4,5 & 7,8 & 42,3 & 4,0 & 4,1 & 2,4 \\
\hline 50 & 12 & $\mathrm{~K}_{2} \mathrm{~S}_{2} \mathrm{O}_{8}-0,01 \mathrm{~m}$ & 140 & 11,2 & 19,9 & 14,0 & 13,7 & 2,0 \\
\hline 50 & 12 & $\mathrm{~K}_{2} \mathrm{~S}_{2} \mathrm{O}_{8}-0,02 \mathrm{~m}$ & 26,6 & 22,3 & 16,1 & 21,0 & 21,2 & 0,9 \\
\hline 50 & 20 & $\mathrm{H}_{2} \mathrm{O}_{2}$ & 22,5 & 15,9 & 29,2 & 14,4 & 14,7 & 2,0 \\
\hline 80 & 12 & ${ }_{12}$ & 6,7 & 8,4 & 20,1 & 8,7 & 8,5 & 2,3 \\
\hline 50 & 24 & Соле" Мора & 27,0 & 25,1 & 7,0 & 20,0 & 20,4 & 1,9 \\
\hline 50 & 28 & ,, & 24,0 & 29,7 & 19,0 & 25,2 & 25,2 & 0,0 \\
\hline
\end{tabular}

1. Прийман Р., Паальме Л., Губергриц М., Изв, АН ЭССР. Химия * Геология, 16, № 2, I16 (1967).

2. Лурье Ю. Ю., Химический анализ производственных сточных вод, М., 1963.

3. N orw a y S., Analyst, 91, No. 1079, 113 (1966).

4. Mammeyer R. K., Rafalowitz M., Microchem. Acta, 72, No. 4, 561 (1964).

5. Kullbom S. D., Pollard W. K., S mith H. F., Analyt. Chem., 37, 1031 (1964).
Ннститут химии
Академии наук Эстонской ССР
Поступила в редакцию 6/IX 1967

\author{
R. PRIIMAN, L. PAALME
}

\title{
ISOPROPUULBENSEENI SULFOHAPPE NAATRIUMSOOLA KONTSENTRATSIOONI MÄARAMINE KEEMILISE HAPNIKU- TARVIDUSE JARGI OKSUDATSIOONIL
}

Artiklis antakse isopropüülbenseeni sulfohappe naatriumsoola vesilahuse segus leiduvate $\mathrm{Na}_{2} \mathrm{SO}_{4}, \mathrm{Na}_{2} \mathrm{CO}_{3}$ ja nende hapendumisel molekulaarse hapnikuga tekkinud oksüdatsiooniproduktide keemilise hapnikutarviduse määramise meetod.

Teades oksüdeerimata ja oksüdeeritud sulfosoola keemilist hapnikutarvidust, leitakse molekulaarse hapniku toimel oksüdeerunud sulfosoola hulk.

Samaaegselt määratakse oksüdeerunud sulfosoola huık standardse nn. metüleensinise nueetodiga. Vōrdlus kinnitab esimese meetodi suuremat täpsust (4-15-kordset) ja suhtelist lihtsust.

\section{R. PRIIMAN, L. PAALME}

\section{DETERMINATION OF THE CONCENTRATION OF THE SULFURATED CUMENE SODIUM SALT MIXTURE BY MEANS OF DETERMINING THE CHEMICAL DEMAND OF OXYGEN AT OXIDATION}

Sulfurated cumene sodium salt (I) water mixture with $\mathrm{Na}_{2} \mathrm{SO}_{4}, \mathrm{Na}_{2} \mathrm{CO}_{3}, \mathrm{NaOH}$, and the same mixture previously oxidized with molecular oxygen, were oxidized with $\mathrm{K}_{2} \mathrm{Cr}_{2} \mathrm{O}_{7}$ solution in concentrated $\mathrm{H}_{2} \mathrm{SO}_{4}$. The chemical demands of oxygen were found, and consequently the amount of $\mathrm{I}$ that was oxidized with molecular oxygen.

Simultaneously the percentage of the oxidation of I was determined by standard methylene blue method.

At a comparison of the two determinations it turned out that the first method is nore comfortable and $4-15$ times more accurate. 